\title{
The Rhetoric of Public Health for RHM Scholarship and Beyond
}

\author{
Jennifer Malkowski and Lisa Melonçon
}

Public health, a widely encompassing term often used to describe ways that various stakeholders communicate about and respond to issues of health that effect large populations, tends to be centered on concerns about prevention, containment, empowerment, and advocacy in relation to disease. As a distinct professional field and set of practices, public health is sometimes described and categorized as the branch of healthcare primarily concerned with populations, whereas medicine focuses more on individual health (Public Health, 2019). The American Public Health Association specifies that "while a doctor treats people who are sick, those of us working in public health try to prevent people from getting sick or injured in the first place. We also promote wellness by encouraging healthy behaviors" (para. 2, 2018). In addition, scholars and practitioners in public health track and analyze emergent health patterns, react in times of crises, and provide important insights into the effectiveness of policies, procedures, and responses. Strategies used by public health professionals to "prevent" and "promote" across a variety of health issues and situations often are rhetorical in nature; that is, they center on persuasive strategies and messages intended to move people from words to action. In his state-of-the-art review of health communication inquiry and health promotion, Gary Kreps (2015) notes that "Communication scholarship has made major contributions to promoting public health over the last 50 years" (p. 4). Despite the wide array of interdisciplinary experts equipped to study persuasive communication,

(c) 2019 University of Florida Press 


\section{Editors' Introduction}

according to Kreps, investigation into the strategies used to promote public health goals has thus far largely only "attracted media scholars concerned with the development, implementation, and evaluation of communication campaigns to prevent major health risks and promote public health" (p. 4). Now may be a particularly exigent moment for RHM scholars to join the public health effort. With the increased access to and speed of information due to the internet and mobile technologies, an increased exigency exists to understand more fully the persuasive dimensions and capabilities of communication practices related to public health.

A rhetorical orientation toward the study, practices, and communication of public health emphasizes how language helps to create, organize, challenge, and fragment public health realities. "If Public Health professionals can be viewed as rhetors, the effectiveness of their work, as evinced in their writing and speaking, derives from their ability to convey information persuasively to an audience, convincing people that what they have to say is worth considering, and motivating people to change behavior" (Clark \& Fischbach, 2008, pp. 20-21). Indeed, much of public health work depends on the persuasive aspects and the effectiveness of discourse, and a number of studies have demonstrated that policy communication substantially influences experiences of health and illness. In particular, scholars have articulated the rhetorical quality of health policy debate, have demonstrated the material consequence of public policy language, and have suggested that the sociocultural context determines the range of discursive opportunities available to public officials who seek to amass particular kinds of public response. To this end, Robert Asen (2010) has claimed that "the process of policymaking foregrounds the role of rhetoric as a constitutive force" (p. 129). With direct connections to debates about the material consequences of rhetoric, RHM scholars now argue the relationship between rhetoric and material reality is both evident and critical to the politics of public health. Providing two more recent cases in point, Jennifer Scott et al. (2015) considers how the material realities of the 2014 Ebola outbreak were revealed, concealed, ignored, or exacerbated in calls to develop a new vaccine, and the recent work in RHM by Heidi Lawrence (2018) underscores the importance of rhetoric to ongoing considerations of conversations about vaccine hesitancy.

What the first year of RHM illustrates is that much of the work done by rhetoricians of health and medicine intervenes in pubic conversations either implicitly or explicitly. And when it comes to matters of rhetorical 


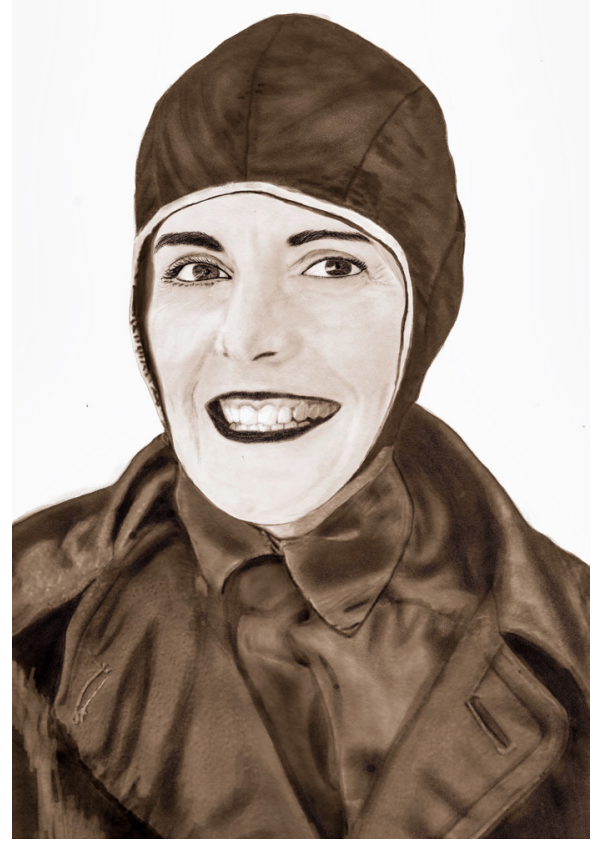

Lisa Keränen (Portrait collage by Josh Prenosil).

public(s) and the connection to health, more work remains to be done around the concept of "the public" as a linguistic and practical commonplace. Thus, this special issue brings into sharp focus the necessity to coordinate efforts to explore the network of meaning and actions associated with the conceptualization and management of disease and well-being across populations, borders, and histories so as to present a new commonplace of the rhetoric of public health.

\section{Rhetoric of Public Health, Publics Theory, and Medicine}

As an area of distinct inquiry, the rhetoric of public health is principally concerned with better understanding the conceptualization and representation of public health as a capacious site that includes different kinds of discourses framed by public health exigencies and audiences. To do the work of public health requires a multitude of discourses-verbal, aural, visual, 


\section{Editors' Introduction}

multimodal-delivered in any number of ways-print, online, door-todoor, community meetings, mobile - across a variety of stakeholders where the value of public health depends on the persuasive aspects and the effectiveness of those discourses and approaches. Indeed,

An important component of Public Health work involves communication-that is, helping the public gain a better understanding of how to engage in a healthy lifestyle and avoid behaviors that are likely to interfere with that goal. Therefore, Public Health professionals can be viewed as rhetoricians, who must become skilled in persuasive argument. (Clark \& Fischbach, 2008, p. 20)

Rhetoricians of public health document the social, cultural, economic, and political aspects of public health management across time, space, and place to assist and, ideally improve, public health realities, as well as investigate how communal realties of contemporary health citizenship expand and complicate publics theorizing for the discipline of rhetoric more generally.

Frequently, the concept of "the public" acts as a commonplace that seemingly everyone knows and understands. But who/what exactly comprises "the public" of public health? From a rhetorical standpoint, public health's "public" can be understood as discursively constructed and increasingly complex, not simply a descriptor of a target audience. Scholars working in RHM have contributed a small but growing body of literature that theorizes publics as a distinct type of health community that is equipped with rhetorical tenacity.

One scholar, Lisa Keränen, has led the way in thinking through publics and RHM. As we continue to honor some of the founders of RHM, we offer a steampunk-inspired portrait of Keränen to pay tribute to her commitment to this area and to RHM more broadly. In 2014, Keränen edited a special issue of the Journal of Medical Humanities aptly titled "Medicine and Its Publics" and affirmed that publics theory adds something extremely valuable to the study of medicine, but that it also complicates well-worn approaches to understanding the public of public health. Specifically, Keränen (2014b) suggested

a rhetorical perspective on publics [.. . ] advances a participatory, dialogic model wherein citizens self-organize around issues of interdependent concern in a public sphere that need not be limited 
to geographical space.... From this perspective, we can appreciate biomedical and health discourses and practices as the result of complex sets of interacting rhetorical performances that bridge public, private, institutional, and technical concern. (p. 104)

Coining the term "medical publics" to denote complex networks of people that individually intersect with medicine, but that, as a collective, may operate independently and unofficially with regard to the policies and practices of Western medicine, the special issue was dedicated to exploring how "a rhetorical understanding of publics contributes to the medical and health humanities" (Keränen, 2014b, p. 103). Additionally, it outlined an agenda for rhetoricians interested in publics theorizing in/for RHM, as well as medicine by encouraging rhetoricians to deploy the tools and vocabularies of the tradition to describe, explain, and evaluate the status of various publics. This RHM special issue builds upon and advances this line of work but turns attention to the specific branch of medicine dedicated to the health of groups in our society: public health.

Importantly, approaching publics from a rhetorical stance can assist the practical needs of public health as well; after all, "Projects in rhetoric of health and medicine, in general, aim to be useful. Their usefulness often lies in their ability simply to pose questions that are prior to the questions typically posed by health researchers" (Segal, 2009, p. 228). Beyond medicine and beyond the intricacies, characteristics, or functions of any one particular medical public, therefore, this $R H M$ special issue starts at a more macro level to investigate questions about the public of public health, such as: How can/should the "public" of public health be theorized? How do the "publics" of public health compare to the notion of medical publics, health citizens, and other concepts as they have been employed in RHM theorizing? And, how do communal realties of contemporary health citizenship expand and complicate publics theorizing for the discipline of rhetoric more generally?

Investigating answers to these questions works in concert with previous and ongoing work in the area of publics theory to further extend "conversations about the coevolving relations among biomedicine, health and publics," while acknowledging the "vibrant multiplicity of public engagements with health and medical processes" (Keränen, 2014, p. 103). Understanding the nature and influence of "rhetorical performances" associated with public health practices, policies, and outcomes as intersecting with, but distinct from, medicine and medical publics affords new opportunities to 


\section{Editors' Introduction}

consider a broader array of conceits influencing how actors understand and navigate their roles in relation to other individuals and institutions of health.

\section{Summary of the Special Issue}

As noted above, this collection and conceptualization of publics and public health study follows the lead of a specialized subset within the broader discipline of rhetoric. Just as the literature on medical publics draws on Gerard Hauser's (1999) work, contributors to this special issue take as their starting place these assumptions: variety exists across different health definitions and experiences; certain health conditions, issues, and controversies attract the attention of individuals who disagree with dominant understandings of health, and; contested sites of medical deliberation provide valuable resources for investigating how medical discourses operate in relation to the overall publicness of health. Each of the projects showcased in this collection address how "the public" of public health gets conceptualized, managed, and mobilized through rhetorical means. In doing so, collectively, these authors help to articulate, appreciate, and ideally improve the various ways that public health — as a state, as a field, and as a commodity —operates. In an effort to speak to the actors and institutions of public health about the persuasive status of public health practices more directly, each contribution also offers commentary on the way rhetorical theory illuminates, problematizes, and influences the health of various publics and the ways that public health as an institution and praxis might heed the advice of rhetoricians to advance larger health agendas.

Building on Jenell Johnson's (2016) theory of visceral publics, Emily Winderman, Robert Meija, and Brandon Rogers investigate how sensory engagement mobilizes individuals against perceived health threats. Conducting a comparative analysis of two different public health images (an advertisement and a photograph) from two different points in history (early 20 th century and early 21 st century) for two different health conditions (Typhoid and Zika), their rhetorical analysis reveals remarkable similarities when it comes to how sight and smell are invoked via mass media to incite public response to disease risk. In doing so, these authors critique the persistent, formulaic nature of public health messaging and problematize the longstanding raced, classed, and gendered consequences of miasmic thinking. 
The next essay performs an in-depth case study of U.S. public health nutrition policy and, in doing so, expands a key rhetorical concept, stasis, in innovative ways. Adele Hite and Andrew Carter illustrate the value of rhetorical theory for understanding how public health means may, ultimately, interfere with public health goals. Hite and Carter start with stasis theory and merge it with Mohan Dutta's (2010) assumption by which health communication "obscure[s] scientific uncertainties and social norms and values that underlie policy creation." Then, the authors apply their adapted version of stasis theory to the Dietary Guidelines for Americans, track policy communication across time to unpack assumptions underlying the "calories in calories out" clause to reveal how scientific claims are translated into policy via dominant values, and assess how those value-laden policies influence future scientific possibilities. In doing so, Hite and Carter adeptly demonstrate how good intentions may produce blind spots for public health overall, oversights that rhetorical theory and methods help illuminate and address.

In the final research article in this issue, Kari Campeau's study makes use of rhetorical field methods to consider the participatory function of vaccination refusals. Results from her ten-month ethnography designed and conducted in partnership with a Somali-run health center reveal the limitations of homogenizing groups when seeking to understand the/a "public" of public health, especially when public health efforts are aimed at marginalized experiences. Rhetorical sensitivity, as Campeau's study demonstrates, offers a means to understand divergent health behaviors, to recognize the value of diverse voices for public health agendas, and to advance more socially just and ultimately sustainable public health practices.

Continuing $R H M$ 's commitment to alternate submission types, Elizabeth Angeli and Christina Norwood contribute a persuasion brief focused on public health crisis response to the 2014 Ebola outbreak. Analyzing both interview data and a collection of multimodal communication produced by institutions charged with improving protocols for disease management while the outbreak occurred, Angeli and Norwood illuminate and theorize the "rhetorical underpinnings" of public health work. They conclude that successful crisis response requires actors to trust expertise, rely on gut feelings, and consider various audiences and contexts when designing and assessing disease risk and response. The rhetorical concept of techne offers both an explanatory and prescriptive framework for advising future public health disease management efforts, and their persuasion brief closes with specific tools and recommendations for moving forward. 


\section{Editors' Introduction}

This special issue also includes an interview with two scholars invested in advancing publics theorizing for health and medicine: J. Blake Scott \& Lisa Keränen, contributors to the special issue indexed above. In concert with the fall 2018 Public Address Preconference symposium entitled, "Health Rhetoric and Social Justice," Scott and Keränen sat down together to discuss the status of and potential for the rhetoric of public health as a distinct field of inquiry. Equipped with a list of open-ended questions, the scholars were asked to reflect on the intersections of rhetoric, health, and medicine, to assess the status of medical publics theorizing since their collaboration on the $2014 \mathrm{JMH}$ special issue, and to consider the value of rhetorical study for understanding and contributing to public health specifically. The results of the interview were recorded, transcribed, and made available online: https://stars.library.ucf.edu/rhm/vol2/iss2/1/.

We are particularly proud that this issue features a range of scholars, many of whom are at the early stages of their careers. As a community committed to mentoring the next generation of RHM scholars, we are delighted to feature so many new perspectives. We also want to take a moment to highlight the fact that $R H M$ special issues are solicited in a different way than many journals. We have described the proposal review process in detail elsewhere (http://medicalrhetoric.com/decision-process-for -rhm-special-issue/), but we wanted to highlight three important aspects of $R H M$ 's process. First, one of the regular co-editors works with the special issue editor(s) to mentor and to assist with production. Second, the proposals are reviewed anonymously by the special issue editors and then by members of our editorial board. We instituted this step to allow for a more objective reading of the proposals as they relate to the special issue topic and the scope of RHM generally. Finally, the accepted proposals then go through the same rigorous, constructive review process as any submission to the journal. For this special issue we accepted seven proposals. The four pieces in this issue (three research articles and one persuasion brief) were the pieces that came through review in time for publication.

\section{Rhetoric of Public Health \& The Future}

This issue of $R H M$ continues and complicates ongoing scholarly efforts focused on "publics" to inaugurate a research trajectory for scholars invested in the public nature of health specifically and - through both methods and findings - contributes innovative approaches to public health happenings 
overall. A rhetorical viewpoint is advantageous to the status of public health because the stance readily assists in integrating voices at the margins (for example, from patients to the displaced, to minorities and women, etc.) into official communication more broadly, a task that seems increasingly difficult in a more globalized world but nonetheless necessary given the complexities of public health threats. To this end, the rhetorical perspective also contributes innovative, mixed methods research designs to bring close textual analysis into play with more participatory approaches (see Melonçon \& Scott, 2018; Middleton et al., 2015). Identifying, understanding, and integrating a variety of experiences of public health-via close, systematic consideration of discourses surrounding and comprising public health—can more earnestly represent public health dilemmas. Furthermore, facilitating cross-methodological and cross-disciplinary possibilities via the rhetorical perspective can model intellectual and practice-based behaviors needed to assess and address public health concerns more comprehensively. Thus, rhetorical sensibilities provide a fruitful way to bring in specific theoretical approaches, to expose and critique and ultimately change the various structures they may inhibit, and to influence the various actors influencing the public health topics specified.

Rhetoricians of health and medicine offer much in terms of helping to navigate the complexities of contemporary disease and risk management and this volume assists in ushering in rhetoricians to deliberations about public health across issues, needs, and disciplinary divides moving forward. As "a humanistic and interpretive act," whereby the critic "takes up a text and recirculates it" to see the world from a different angle (Keränen, 2010, p. 23), rhetorical criticism as a research method, when mindfully constructed, can present opportunities for meaningful engagement across audiences of public health, audiences that can become divided over issues of expertise, allocation of resources, or management of risk. The emphasis on theory and practice provides scholars (and students) the opportunity to see new ways of approaching large (seemingly overwhelming), multifaceted problems, of contributing to an emerging field, and of gaining an understanding of and propensity for key concepts that inform and unite scholars in this area. The emphasis on theory and practice provides public health practitioners and participants with a more holistic understanding of public health's complexities and the ways that attentive language can help influence those realities. Future studies of timely topics in key areas of inquiry within the rhetoric of public health include: a) environmental and risk communication; 


\section{Editors' Introduction}

b) contemporary health citizenship; c) global disease politics and ethics; d) social, political, and cultural disparities in public health; and, e) data visualizations and technological innovations surrounding public health management. While we could certainly add more to this list, we feel that these areas are the most pressing and would benefit the most from a rhetorical viewpoint.

Public health communication, policies, and practices take place in the communities and locations where people live, work, and play. Issues in public health readily traverse national, cultural, and political divides. Distinguishing research in the rhetoric of public health uniquely, more directly emphasizes these borderless, communal realties of contemporary health citizenship, intentionally expands and complicates publics theorizing to better respond to contemporary health threats, and helps to monitor the emergence of global biomedical agendas premised on understandings of health as a population level phenomenon. As each of the contributors to this volume demonstrate, rhetorical scholarship can aid in understanding and promoting the public's health by identifying opportunities for partnership across each domain, domains that share an understanding of and appreciation for the ways that persuasion matters deeply to matters of social wellbeing, public participation, and individual health. Choreographing this body of work into a cohesive whole will help to streamline vocabulary, theorizing, and concepts at the intersections of public health and rhetoric. In doing so, it is our hope, practitioners studying public health rhetorics can advance the area of inquiry more readily, feel supported in those endeavors, and communicate legitimacy across audiences more widely.

\section{References}

American Public Health Association. (2018). What is Public Health? Retrieved from https://www.apha.org/what-is-public-health

Asen, Robert. (2010). Reflections on the role of rhetoric in public policy. Rhetoric and Public Affairs, 13(1), 121-143.

Clark, Irene L., \& Fischbach, Ronald. (2008). Writing and learning in the health sciences: Rhetoric, identity, genre, and performance. The WAC Journal, $19,15-28$.

Dutta, Mohan Jyoti. (2010). The critical cultural turn in health communication: Reflexivity, solidarity, and praxis. Health Communication, 25(6-7), 534-539.

Public Health and Medicine. (2019). Retrieved from https://www.hsph.harvard .edu/about/public-health-medicine/ 


\section{Malkowski and Melonçon}

Hauser, Gerard A. (1999). Vernacular voices: The rhetoric of publics and public spheres. Columbia: University of South Carolina Press.

Johnson, Jenell. (2016). “A man's mouth is his castle”: The midcentury fluoridation controversy and the visceral public. Quarterly Journal of Speech, 102(1), $1-20$.

Keränen, Lisa. (2014a). Medicine, health, and publics [Special issue]. Journal of Medical Humanities, 35(2).

Keränen, Lisa. (2014b). Public engagements with health and medicine. Journal of Medical Humanities, 35(2), 103-109.

Kreps, Gary L. (2015). Health communication inquiry and health promotion: A state of the art review. Journal of Nature and Science, 1(2), 1-12.

Lawrence, Heidi Y. (2018). When patients question vaccines: Considering vaccine communication through a material rhetorical approach. Rhetoric of Health E Medicine, 1(1-2), 161-178.

Melonçon, Lisa, \& Scott, J. Blake (Eds.). (2018). Methodologies for the rhetoric of health and medicine. New York, NY: Routledge.

Middleton, Michael K., Hess, Aaron, Endres, Danielle, \& Senda-Cook, Samantha. (2015). Participatory critical rhetoric: Theoretical and methodological foundations for studying rhetoric in situ. Lanham, MD: Lexington.

Scott, Jennifer L., Kondrlik, Kristin, Lawrence, Heidi Y., Popham, Susan L., \& Welhausen, Candice A. (2015). Rhetoric, Ebola, and vaccination: A conversation among scholars. POROI, 11(2). Retrieved from https://ir.uiowa .edu/cgi/viewcontent.cgi? referer=https:/www.google.com/\&httpsredir $=1 \&$ article $=1232 \&$ context $=$ poroi

Segal, Judy Z. (2009). Rhetoric of health and medicine. In Andrea Lunsford, Kirt H. Wilson, \& Rose A. Eberly (Eds.), The SAGE handbook of rhetorical studies (pp. 227-246). Los Angeles, CA: SAGE. 
